\title{
Impact of Resource Based View and Resource Dependence Theory on Strategic Decision Making
}

\author{
Ali Raza Nemati \\ Riphah International University, Islamabad, Pakistan \\ Tel: 92-345-590-5581 E-mail: aliraza.nemati@riphah.edu.pk \\ Afkar Majeed Bhatti \\ Riphah International University, Islamabad, Pakistan \\ Tel: 92-333-535-9743 E-mail: Afkar_tg@yahoo.com \\ Muhammad Maqsal \\ Riphah International University, Islamabad, Pakistan \\ Tel: 92-345-956-5435Ｅ-mail: mmaqsal@gmail.com \\ Immad Mansoor \\ Riphah International University, Islamabad, Pakistan \\ Tel: 92-345-580-0451Ｅ-mail: immadmansoor@gmail.com \\ Fariha Naveed \\ Riphah International University, Islamabad, Pakistan \\ E-mail: farihanaveed@riphah.edu.pk
}

\begin{abstract}
This paper aims to investigate different factors determining strategic Decision making. This study attempts to identify the role of RBV and RDT and its impact on strategic Decision making. It has been seen that different strategies has to be made to get competitive advantage keeping in mind external resources and while strategies differ when to get competitive advantage through internal resources such as Human resource and capital Resource. In this research heuristics and bounded rationality acted as moderator to strategic decision making as when decision makers (managers take decisions personal biases and heuristics also get involved.
\end{abstract}

Keywords: Decision making, Resource based view, Resource dependence theory, Heuristics and biases

\section{Introduction}

The purpose of this research paper is to study the impact of internal resources and external resources on strategic decision making. What are the key resources to be considered for strategic decision making? The strategic decision making includes choosing the key factors those determine the performance of an organization in the long run. It doesn't deal with day to day operations decisions. As these decisions considers long term strategy of an organization that's why the internal resources and external resources are being analyzed, for getting competitive advantage. Marsh et al (1988) said that the wider literature on environmental determinism and the role of management choice is relevant here. Strategic decisions (SDs) are among the main means through which management choice is actually affected.

Borut Rusjan (2005) states that business strategy specifies the scope of each business and defines the basis on which a business unit can achieve and maintain a competitive advantage within its industry

In strategic decision making it depends on decisions makers that how do they use the internal resources and external resources available to an organization for its success in the long run. In strategic decision making the decisions are of highest level with great uncertainty and least structured, as these decisions are for long run. The 
internal resources are directly under the control of an organization by effective use competitive advantage can be achieved, as the external resources are to be managed by an organization.

The internal resources include human capital resources, financial resources, technology, plant and equipment, innovative abilities and internal processes systems, these all are directly under the control of an organization and an organization can influence it. While the external resources include the production processes, external links of organization and organizational behavior. The both type of resources are important for strategic decision making, but as on external resources are not being influenced by an organization while the internal resources are being influenced by an organization. The best strategies can be evolved with the combination of both resources by analyzing the threats and opportunities and taking the decisions accordingly.

In general strategy is defined as "the long term direction of an organization". However to be more specific and based on characteristic, it involves, strategy may be defined as the long term direction and scope of an organization to achieve competitive advantage through the configuration of resources within a changing environment for the fulfillment of stakeholders objective and expectations

The rest of the paper has been divided in four parts. Part (II) literature review, Part (III) Model (Theoretical Framework), Part (IV) Research Methodology (V) Discussion \& Conclusion (VI) Limitations

\section{Literature Review}

Roger Enrico, CEO of Pepsi When you are faced with a decision, the best thing is to do the right thing, the next best is to do the wrong thing and the worst thing to do is nothing.

Vassilis Papadakis, Spyros Lioukas and David chambers (1998) says that Strategic decision making has emerged as one of the most active areas of current management research. The area has greatly benefited from such research traditions as behavioral decision theory and transaction cost economics and has recently gained it. The nature of the decision itself, or the SD project, may be important. Research into decision-making cognition and labeling suggests that the same internal or external stimulus may be interpreted quite differently by managers in different organizations or even within the same organizations own momentum .One of the priorities of future research in strategic decision-making the examination of the extent to which variations in strategic decision making processes is explained by variations in organizational, environmental, decision-specific, and managerial factors.

Marsh et al., 1988 says that the wider literature on environmental determinism and the role of management choice is relevant here. Strategic decisions are among the main means through which management choice is actually affected. But empirical research has not been extended to rigorous investigation of the role of management factors, contextual factors, and decision-specific characteristics on the actual strategic decision-making processes.

Marsh et al, 1988 argues that Enterprises are more and more confronted with the consequences of dynamic change caused by the globalization of commerce and by the information flood that is due to the Internet. The radical change of the environment in which companies operate reduces the ability of managers to act on the strategic aspects of their task, and to conduct effective management of operations, in a timely way. Catching and structuring the complexity of the area that is being managed therefore tends to happen less, or less effectively.

Marc Knoppe, (2001) states that "Existing management systems are not in a position to give optimal treatment to the daily data streams, therefore to prepare the best management decisions. The evaluation of chances and risks becomes more difficult day by day. Thus, in practice, the percentage of risky or emotional decisions will be increased, and the strategic decision making process will be dominated by the pressing considerations of short-range planning".

The resource-based view of the firm (RBV) receives great attention in the strategic management literature. Its orientation towards internal analysis of the firm offers to human resource strategic management a valuable conceptual framework, through which to analyze the ways in which firms try to develop their human resources with the aim of transforming them in a sustained competitive advantage" (Wright and McMahan, 1992).

Gerald, et al (2002) studies strategic decision making and suggests that when confronted with complex problems, involving risk and uncertainty; strategists adopt a variety of heuristic modes of thinking and reasoning, in an effort to simplify the processes of judgment and decision making.

The term 'dynamic capabilities' refers to the firm's ability to integrate, build upon and Reconfigure internal and external resources and functional competences to deal with Environments which are constantly evolving (Teece et al., 1997, p.515). 
Dean and Sharfman, (1993); Dutton, (1993) \& Haley and Stumph,(1989) studies the nature of the decision and says that research into decision making cognition and labeling suggests that the same internal or external stimulus may be interpreted quite differently by managers in different organizations or even within the same organization

Vassilis m. Papadakis, Spyros Lioukas and David chambers, (1998) states that "It has been argued that the way managers categorize and label a decision in the early stages of the decision making process strongly influences the organization's subsequent responses . For example, there is evidence that if a decision is perceived as crisis different actions will be taken than if the decision is perceived as an opportunity found that when decisions were interpreted as threats as opposed to opportunities, the decision making process followed was characterized by greater comprehensiveness."

Schneider and Meyer, (1991).The way in which decision makers categorize and label a strategic decision as an opportunity or as a crisis, strongly affects the subsequent processes of decision making. Jackson and Dutton, (1988) says that there is evidence that executives behave in a different way if they perceive a decision to be motivated by an opportunity rather than by a crisis.

Elbanna and John child, (2007) suggests that Firm performance rather than environmental characteristics, such as environmental uncertainty, appears to be the most important moderator of the relationship between the strategic decision-making process dimensions and strategic decision effectiveness. Firms under pressure to improve their performance will tend to employ more rational decision-making processes. The research concluded that decision-specific characteristics played a central role in relation to strategic decisions, with environmental factors playing a less significant role.

George T. Haley, (1997) argued for culture as a dominant variable in decision making styles."However, it is possible to improve the quality of rational decision-making by using appropriate think-tools that is, techniques that help to sharpen perceptions of the complex system"

Mark (1997) concluded that for many reasons, the hardest part of managing an organization today is making the appropriate decision. Once a manager chooses an alternative and knows how

to implement it, he can allocate the resources necessary to achieve the defined goal; but getting to that point can often be a long, complex, and challenging process.

Mahmood Nooraie, (2008) concluded that the difficulty arises when the most preferred alternatives are Unfeasible. This actually defines how well the decision process is carried out. Implementation phase determines how well the selected alternative decision is accomplished, the decision goals are achieved, or problems are solved.

In decision-making phase the quality of the decision-making process output in terms of timeliness or speed of the decision-making, acceptability to interested units and people, and adaptiveness to change can be evaluated. Borut Rusjan (2005) most researchers agree that the main emphasis of strategic decision making is on ensuring the achievement of competitive advantage of an enterprise.

Harrison (1975) suggested that the merger of technical and human factors into the managerial decision-making process is the key to successful decision making. Shawna S. Friday-Stroud and J. Scott Satterfield, (2007) Their decision-making capabilities can be enhanced by using the strategic managerial decision-making process

\section{Figure 1}

RDT: Resource Dependence Theory

RBV: Resource based View

This model tries to explain the relationship of different variables that affects decision making. In this paper, independent variables that are capital resource and human resource support RBV and on the other side the uncertainty and scare resources support RDT, and in the result both RBV and RDT impacts the nature strategic decision making that is dependant variable.RBV more focus on internal resources and rdt focuses on external resources if manager make decision keeping in view one theory then decision might not be $100 \%$ correct .manger might be influenced by one of the theory but for better and good decision manager need combination of both different view and then come to one of the best.

Traditionally competitive strategy relates to how a strategic business unit (SBU), be it a standalone firm or a division of a larger corporation, competes within a particular market, and corporate strategy relates to how a corporation manages a set of businesses (Grant, 2005) 


\section{Hypothesis}

H1: Resource based View and Resource Dependence Theory impacts strategic decision making of the organization.

H2: Manager's decision making is influenced by Heuristics and Bounded rationality.

\section{Discussion}

Decision making first places the process approach to decision research in a historical and theoretical context and provides a critical evaluation of its principal Research methods. Contributors then consider the influence of values, involvement and emotions upon decision making and issues concerning risk and uncertainty.

This paper has studied the relationship of RBV with the capital resources and the human resources, and on the other side the relationship of RDT with uncertainty and scare resources and then the impact of RDT and RBV on strategic decision making as mentioned in the model. The findings presented that the effective performance of human resource and enough capital resources can effects the decision making. If the resources were effective and efficient then the decision making will be effective. The management will take effective decision regarding the organizational goals and objectives. It is the responsibility of a management to find out the strengths and weaknesses and resources that were available to the management. In hypothesis 1 , the RBV influences on the strategic decision making, if resources are available according to needs. This is a supportive statement. The $\mathrm{RBV}$, positively and negatively influences on the strategic decision making process.

Same in the case of RDT, it influences negatively and positively on strategic decision making. The management will definitely measures the uncertainty and scare resources before taking any decision. Same in case of RDT the management have no control on the external resources; it has implications regarding the optimal divisional structure of organizations, recruitment of board members and employees, production strategies, contract structure, external organizational links, and many other aspects of organizational strategy.

In our case the uncertainty and scare resources were the external factors, the management have no control on them, if something went wrong then the decision makers are unable to control that situation, on the other hand the capital resources and human resources were in the control of management, it's the capability of decision makers or management how to utilize them in achieving their goals and objectives. So the uncertainty and scare resources are related to Resource dependent theory and capital and human resources were related to Resource based view, the dominant approach in contemporary strategic management is the RBV

When decision makers take decisions personal biases are being involved. As these biases are involved in day to day decision making, in the same way these biases are involved in strategic decision making of the organization. With respect to RDT Internal resources are directly under control of firm so strategist can have better information about internal resources as compared to external resources so it is quite possible that they might make strategies by more focus on internal resources, they might not go for the combination of Resource based strategy. As well as information asymmetry plays a vital role in biases decision making as even after eliminating the complete agency problem they would have access to information up to a certain level that is also the concept of bounded rationality.

Even if the decision maker get the complete access to the information required for a strategy even then interpretation varies. After that we can relate it to their approaches, Syntactic, Symantec and pragmatic approach this is explained by Paul R. Carlile in (2002).

The source of value from the RBV perspective is that value flows from resources that possess specific attributes. The direct causal links between assets and capabilities exhibiting the desired attributes and the value customers perceive them to provide has, however, not been a focal point of the RBV the resource based view and value alignment.

Resource dependency theory fails to properly value a sense of rationality in the organization, the theory does help explain the environment and context in which individual decisions are made within organizations

This final section of paper will examines how different theoretical approaches affect and impact on strategic decision making. Here our research will take support of two different theories like Resource Base View (RBV) and Resource Dependency Theory(RDT) to prove how important to know about internal and external resources allocation to make strategic decision for to get competitive advantage.

According to different research, competitive advantage is a function of industry analysis, organizational governance/ Management and firm effects in the form of resource advantages and strategies.

A firm's resources consist of all assets both tangible and intangible, human and nonhuman that are possessed or 
controlled by the firm and that permit it to devise and apply value-enhancing strategies. These value enhancing strategies formulate by the top management under the umbrella of strategic management process.

The strategic management process consist of how allocate and craft strategies to get Unique resources and capabilities are discussed under a variety of names, e.g. distinctive competences, core competences, invisible assets, core capabilities, internal capabilities, embedded knowledge, corporate culture, and unique combinations of business experience.

Organizational success in resource dependency theory (RDT) is defined as organizations maximizing their power. Research on the bases of power within organizations began as early as Weber (1947) and included much of the early work conducted by social exchange theorists and political scientists. Generalization of power-based arguments from intra-organizational relations to relations between organizations began as early as Selznick (1949). RDT characterizes the links among organizations as a set of power relations based on exchange resources. RDT also explaining behaviour, structure, stability, and change of organizations.RBV usually helps to formulate the firm's business level strategies.

Here relationship of both two theories with respect to strategic decision making is mentioned below that with give better understanding how strategic decision making process is also influenced by RDT and RBV.

What we can conclude is, the nature of strategies and strategic decision making changes with the respect to if strategies are being made according to using internal resources as their competitive advantage and if strategies are being made to get competitive advantage with respect to external resources.

\section{Table 1}

\section{Limitations}

This paper investigates the relationship and impact of RDT and RBV on strategic Decision making. More theories can be incorporated to make the model more appropriate, More Literature review can be done to enhance the literature support. Questionnaire tool can also and with the help of that correlation, regression and factor analysis can be done very easily.

\section{References}

Barry C, \& Gerstman J. (2007). The resource-based view and value: the customer-based view of the firm. Journal of European Industrial Training Emerald Group Publishing Limited, Vol. 31 No. 1, pp. 19-35

Bolanos R, Fontela E, Nenclares A., and Pastor P. (2005). Using interpretive structural modeling in strategic decision-making groups. The Emerald Research Management Decision, Vol. 43 No. 6, pp. 877-895

Dean J., \& Sharfman P. (1993). Procedural rationality in the strategic decision making process. Journal of Management Studies, 30 (3), pp. 587-610.

Elbanna1, child j. (2007). Influences on strategic decision effectiveness: development and test of an integrative model. Strategic management journal, 28: 431-453.

George T. Haley. (1997). A strategic perspective on overseas Chinese networks' decision making. Management Decision, 35/8 587-594

Gerard p, hodgkinson, et al. (2002). Further reflections on the elimination of framing bias in strategic decision making. Strategic management journal, 23: 1069-1076.

Grant, R.M. (2005). Contemporary Strategy Analysis. Basil Blackwell, Oxford

Harary, F. (1969). Graph Theory. Addison-Wesley, Reading, MA.

Harrison F. (1975). The Managerial Decision-making Process. Houghton Mifflin Company, Boston, MA.

Jackson SE, \& Dutton JE. (1988). Discerning threats and opportunities. Administrative Science Quarterly, 33(3): 370-387.

Knoppe M, \& Siemensstra A. (2001). Artificial Intelligence as a Decision Tool for Efficient Strategic and Operational. Springer-Verlag Berlin Heidelberg, pp. 20-31, 2001.

Mark S, (1997). Delaying decisions stifles: industrial management decision-making progress. Pacific Business News, Vol. 23, pp. 37-9.

Marsh P, Barwise K \& Wensley R. (1988). Managing Strategic Investment Decisions in Large Diversified Companies. London Business School, Center for Business Strategy Management.

Nooraie M. (2008). Decision magnitude of impact and strategic decision-making process output. The mediating impact of rationality of the decision-making process Decision. Emerald Group Publishing Limited, Vol. 46 No. 
4, pp. $640-655$ q.

Paul R, Carlile. (2002). a pragmatic view of knowledge and boundaries: boundary objects in new product development. Organization science, vol. 13, no. 4, July-august 2002, pp. 442-455

Rajagopolan N, Rasheed A., and Datta K. (1993). Strategic decision processes: critical review and future directions. Journal of Management, Vol. 2, pp. 349-84.

Rue L, Bayrs L. (1986). Management Theory and Application, 4th ed., Irwin, Homewood.

Rusjan B. (2005). Model for manufacturing strategic decision making. International Journal of Operations \& Production Management. Emerald Group Publishing Limited. Vol. 25 No. 8, 2005pp. 740-761.

Schneider SC. (1989). Strategy formulation: the impact of national culture. Organization Studies, 10(2): $149-168$.

Shawnta S. Stroud F, and Sutterfield J. (2007). A conceptual framework for integrating six-sigma and strategic management methodologies to quantify decision making. The TQM Magazine, Vol. 19 No. 6, pp. 561-571.

Simon, H.A. (1969). The Sciences of the Artificial. MIT Press, Cambridge, MA

Vassilis M, lioukas P, \& chambers D. (1998). strategic decision-making processes: the role of management and context. Strategic management journal, Vol. 19, 115-147

Wright M, McMahan C. (1992). Theoretical perspectives for strategic human resource management. Journal of Management, Vol. 18 No.2, pp.295-320

Table 1.

\begin{tabular}{|c|c|c|c|c|}
\hline Theories & Resource Base view & $\begin{array}{l}\text { Resource } \\
\text { Theory }\end{array}$ & Dependency & Decision Making \\
\hline Approaches & $\begin{array}{l}\text { The Industrial Organizational } \\
\text { Approach } \\
\text { - } \quad \text { Competitive advantage } \\
\text { - } \quad \text { Economies of scale } \\
\text { - } \quad \text { Resource allocation } \\
\text { - Competitive rivalry }\end{array}$ & \multicolumn{2}{|c|}{$\begin{array}{c}\text { The Sociological Approach. } \\
\text { • } \quad \text { Structure } \\
\text { - } \quad \text { behavior }\end{array}$} & $\begin{array}{l}\text { Strategic decision making } \\
\text { process consist of both } \\
\text { industrial and sociological } \\
\text { approaches. }\end{array}$ \\
\hline Level of strategy & Business Level strategies & \multicolumn{2}{|c|}{ Dynamic strategies } & Both \\
\hline Type of Resources & Internal Recourses & \multicolumn{2}{|c|}{ External Resources } & $\begin{array}{l}\text { Both need for strategic } \\
\text { decision making process. }\end{array}$ \\
\hline
\end{tabular}

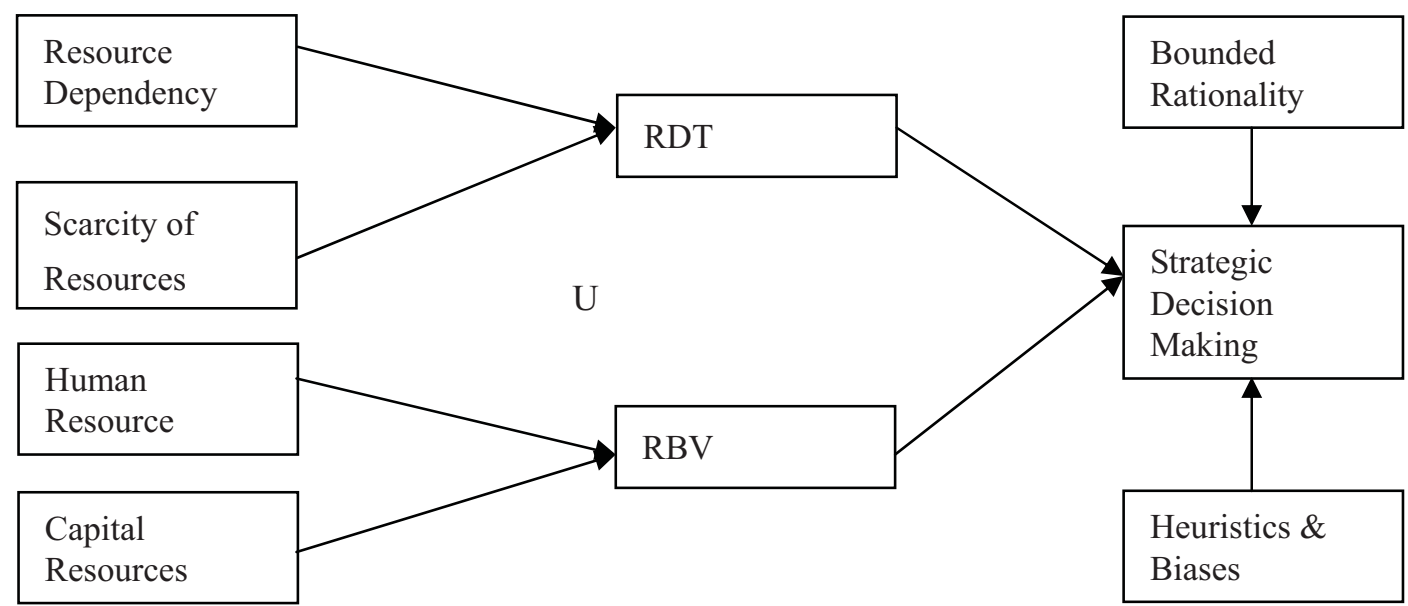

Figure 1. Theoretical Framework 